Article

\title{
Growth of $\mathrm{NbC}$ Thin Film Using $\mathrm{CH}_{4}$ as a Carbon Source and Reducing Agent
}

\author{
Kwan-Woo Kim ${ }^{1,+}$, Bum Jun Kim ${ }^{2,+}$, Sang Hoon Lee ${ }^{1}$, Tuqeer Nasir ${ }^{2}{ }^{\circledR}$, Hyung Kyu Lim ${ }^{1}$, \\ Ik Jun Choi ${ }^{1}$, Byung Joo Jeong ${ }^{1}$, Jaeyeong Lee ${ }^{3,4}$, Hak Ki Yu ${ }^{3,4}$ and Jae-Young Choi ${ }^{1,2, *}$ \\ 1 School of Advanced Materials Science and Engineering, Sungkyunkwan University, Suwon 16419, Korea; \\ kkw8904@skku.edu (K.-W.K.); alfhdj@gmail.com (S.H.L.); hyungkyu1992@gmail.com (H.K.L.); \\ cksoon16@gmail.com (I.J.C.); jbj929@gmail.com (B.J.J.) \\ 2 SKKU Advanced Institute of Nanotechnology, Sungkyunkwan University, Suwon 16419, Korea; \\ kbj454@skku.edu (B.J.K.); tuqeernasir166@gmail.com (T.N.) \\ 3 Department of Materials Science and Engineering, Ajou University, Suwon 16499, Korea; \\ smuff20@ajou.ac.kr (J.L.); hakkiyu@ajou.ac.kr (H.K.Y.) \\ 4 Department of Energy Systems Research, Ajou University, Suwon 16499, Korea \\ * Correspondence: jy.choi@skku.edu; Tel.: +82-31-290-7353 \\ + These authors contributed equally to this study.
}

Received: 16 August 2018; Accepted: 23 October 2018; Published: 24 October 2018

check for updates

\begin{abstract}
Transition metal carbides (TMCs) have high melting points, hardness, and chemical stabilities in acidic media. In this work, a chemical vapor deposition method using $\mathrm{CH}_{4}$ as a carbon source and reducing agent was employed to make an $\mathrm{NbC}$ film. $\mathrm{NbCl}_{5}$ carried by Ar gas was used as an $\mathrm{Nb}$ precursor. An $\mathrm{NbC}$ thin film, deposited on a $c$-plane sapphire, exhibited a preferential orientation of the (111) plane, which can be explained by domain-matching epitaxy. A nanoindentation test showed that the $\mathrm{NbC}$ film with the preferential orientation of the (111) plane was stronger than that with a random orientation. Moreover, the results showed that $\mathrm{H}_{2}$, which is conventionally used as a reducing agent in $\mathrm{NbC}$ synthesis, degraded the crystallinity and hardness of the fabricated $\mathrm{NbC}$.
\end{abstract}

Keywords: transition metal carbides (TMCs); chemical vapor deposition (CVD); $\mathrm{NbC}$ film; reducing agent; $c$-plane sapphire; preferential orientation; domain matching epitaxy (DME)

\section{Introduction}

Transition metal carbides (TMCs) have attracted significant attention as materials with high melting points, hardness, chemical stabilities in acidic media, and thermal stabilities [1-5]. Owing to these unique properties, they have been used in various applications such as cutting tools $[6,7]$, wear-resistant materials [8], and hard electrical contacts [9]. Recently, TMCs are being increasingly utilized as supporting materials for various electrocatalyst materials $[10,11]$ or as electrocatalyst materials themselves [12,13]. Among the various carbide materials, niobium carbide $(\mathrm{NbC})$ has excellent abovementioned properties (highest melting point: $3610{ }^{\circ} \mathrm{C}$, high Young's modulus: 380-480 GPa) and superconducting properties (below $12 \mathrm{~K}$ ), which make it promising for various applications such as a reinforced phase in an iron matrix, hard coating, and wear protection [14-17]. Furthermore, $\mathrm{NbC}$ is potentially applicable as an electrical contact coating material owing to its low electrical resistivity $\left(3.5 \times 10^{-5} \Omega \cdot \mathrm{cm}\right)$ [18] and excellent wear-resistance [19], replacing the noble metal with a low wear resistivity and high cost.

Conventionally, the synthesis of an $\mathrm{NbC}$ thin film is performed by the direct reaction between $\mathrm{Nb}$ metal and carbon owing to the very high melting point $[20,21]$. However, as the melting point 
of $\mathrm{Nb}$ reaches $2744{ }^{\circ} \mathrm{C}$, a chemical compound containing $\mathrm{Nb}$ such as $\mathrm{NbCl}_{5}$ (melting point: $205^{\circ} \mathrm{C}$ ) was used as a precursor [22,23]. $\mathrm{Nb}$ flux can be obtained by heat treatment of $\mathrm{NbO}_{x}$ in a reducing atmosphere (hydrogen gas or additives such as $\mathrm{NaF}$ ); however, this reaction has a disadvantage as a high temperature of $1000{ }^{\circ} \mathrm{C}$ (or larger) is required [24-26].

In this study, we aimed to synthesize $\mathrm{NbC}$ thin films using methane $\left(\mathrm{CH}_{4}\right)$ gas as a source that provides carbon as well as a reducing atmosphere. $\mathrm{NbCl}_{5}$ was used as a precursor of $\mathrm{Nb}$. An analysis of the crystal structure for each flow rate of $\mathrm{CH}_{4}$ was performed to optimize the production of high-quality $\mathrm{NbC}$ films without the formation of oxides. In addition, the mechanical, electrical, and thermal properties of $\mathrm{NbC}$ can vary owing to the difference in the atomic arrangement depending on the crystal orientation of the $\mathrm{NbC}$ thin film (conventionally, the rock-salt $\mathrm{NbC}$ crystal structure has anisotropic properties between (111) and (100) planes). Therefore, we studied the preferential orientation of $\mathrm{NbC}$ depending on the type of substrate, and changes in physical properties depending on structural differences in terms of crystallinity (single-crystal or polycrystal) and crystal orientation.

\section{Materials and Methods}

\subsection{Preparation of Coatings}

Growths of $\mathrm{NbC}$ were performed on a single-crystal c-plane sapphire substrate (Namkang Hi-tech Co., Ltd., SaR 100-500, Gyeonggi-do, Korea) and single-crystal Si (100) substrate using a quartz-tube furnace. Single-crystal Si (100) substrates were prepared by dipping a silicon thermal oxide wafer in an $\mathrm{HF}: \mathrm{H}_{2} \mathrm{O}$ solution with a volume ratio of 1:1 for $1 \mathrm{~min}$. A schematic of the reaction system is shown in Figure 1a. $\mathrm{NbCl}_{5}$ (Alfa Aesar, \#11548, Ward Hill, MA, USA), used as an $\mathrm{Nb}$ precursor, was placed in a stainless-steel canister, which was heated by a heating mantle. The sublimed $\mathrm{NbCl}_{5}$ and $\mathrm{Ar}$ carrier gas were introduced into the tube through a $\frac{1}{4}$-inch stainless-steel gas line, which was wrapped and heated by a commercial heating tape. The temperatures of the canister and line were maintained at 140 and $160{ }^{\circ} \mathrm{C}$, respectively. The substrates were loaded into the tube furnace and the system was pumped down to vacuum and refilled with Ar gas to obtain atmospheric pressure. The furnace temperature was increased to $900{ }^{\circ} \mathrm{C}$ within $40 \mathrm{~min}$ in an $\mathrm{Ar}-\mathrm{CH}_{4}$ or $\mathrm{Ar}-\mathrm{CH}_{4}-\mathrm{H}_{2}$ environment. The gas flow rates of $\mathrm{Ar}$ and $\mathrm{H}_{2}$ were $200 \mathrm{sccm}$, while that of $\mathrm{CH}_{4}$ was in the range of 5 to $200 \mathrm{sccm}$. After the temperature reached $900{ }^{\circ} \mathrm{C}$, the growth of $\mathrm{NbC}$ was initiated by introducing another flow (200 sccm) of Ar carrier gas through the canister to the furnace. After the growth for $30 \mathrm{~min}$, the $\mathrm{Nb}$-precursor supply line was closed, and the samples were rapidly cooled under the Ar environment.

(a)

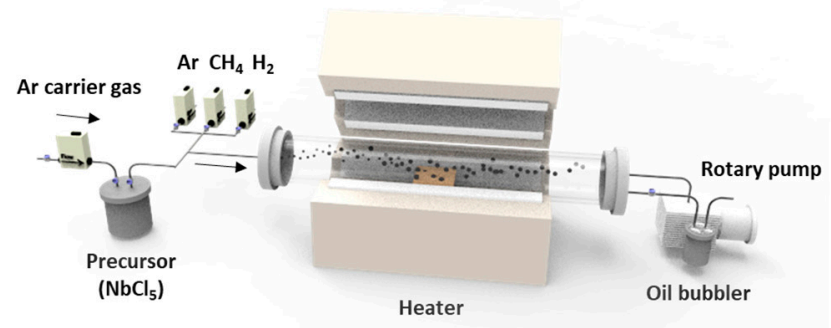

(b)

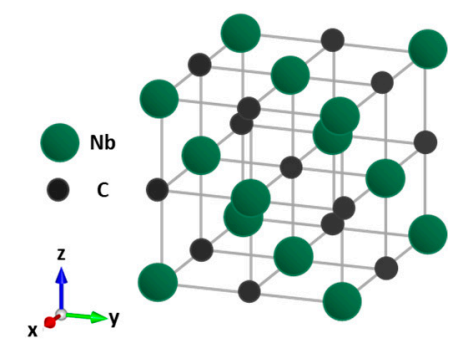

Figure 1. (a) Schematic of the chemical vapor deposition (CVD) reaction system; (b) Crystal structure of $\mathrm{NbC}$.

\subsection{Structure and Property Characterization}

An X-ray diffractometer (XRD) (Bruker D8-Advance with monochromated $\mathrm{Cu}-\mathrm{K} \alpha 1$ radiation; scan rate of $0.05^{\circ} / \mathrm{s}$, Billerica, MA, USA) was used for identification of the samples. The surface morphologies of the samples were investigated by scanning electron microscopy (SEM) (Hitachi, S-4800, Tokyo, Japan). Transmission electron microscopy (TEM) (JEOL, JEM-2100F, at 200 kV, Tokyo, Japan) was employed to analyze the structures of the samples. The TEM sample was prepared by scraping 
off the $\mathrm{NbC}$ onto the TEM grid. A pole figure analysis was conducted to study the symmetry of the sample using an $\mathrm{X}$-ray diffractometer (PANalytical, $\mathrm{X}^{\prime}$ pert $\mathrm{PRO}$ using $\mathrm{Cu}-\mathrm{K} \alpha$ radiation, Westborough, MA, USA, $\chi: 0^{\circ}-75^{\circ}$ and $\varphi: 0^{\circ}-360^{\circ}$ at $2 \theta$ of $\left.40.32^{\circ}\right)$. The mechanical properties of the $\mathrm{NbC}$ samples were characterized by a nanoindentation tester (Anton Parr, Graz, Austria, ultra-precision surface mechanical analyzer). The nanoindentation tests have been performed using a Berkovich diamond indenter. The as-received radius of the tip was $50 \mathrm{~nm}$, and the tip was calibrated on a fused silica reference sample. The hardness and elastic modulus of samples were obtained by averaging the results of 5 indents. However, for the $\mathrm{NbC}$ film grown in the absence of $\mathrm{H}_{2}$ on a sapphire substrate, only a single indentation was performed due to damage that could be caused to the indenter because of the hardness of the sample.

\section{Results and Discussion}

\subsection{Morphology and Structural Characterization}

$\mathrm{NbC}$ has a cubic crystal rock-salt structure (lattice constant $=4.47 \AA$ ), as shown in Figure $1 \mathrm{~b}$. In order to reveal the variations of the $\mathrm{NbC}$ growth depending on the flow rate of $\mathrm{CH}_{4}$, type of substrate, and presence of $\mathrm{H}_{2}$, we performed XRD and SEM analyses, see Figure 2. With the increase in the flow rate of $\mathrm{CH}_{4}$ from 5 to $100 \mathrm{sccm}$, the $\mathrm{NbO}$ peak (Joint Committee on Powder Diffraction Standards (JCPDS) No. 43-1290) decreases, while the intensity and sharpness of the peak at $2 \theta=34.73^{\circ}$ (JCPDS No. 38-1364) [27], corresponding to the NbC (111) plane, increase in the XRD patterns, see Figure 2a). The XRD patterns on a logarithmic scale are also presented in Figure S1. $\mathrm{Nb}$ oxide was formed by a reaction between oxygen remaining in the furnace and $\mathrm{Nb}$ precursor $\left(\Delta G_{\mathrm{f}}\right.$ of $\mathrm{NbO}$ at $300 \mathrm{~K}$ is $-391.77 \mathrm{~kJ} / \mathrm{mol}$, while that of $\mathrm{NbC}$ at $300 \mathrm{~K}$ is $-136.878 \mathrm{~kJ} / \mathrm{mol}$ ); $\mathrm{CH}_{4}$ acts not only as a carbon source in the $\mathrm{NbC}$ formation but also as a reducing agent to reduce the oxide. The $\mathrm{NbC}(111)$ peak further increased with the increase in the $\mathrm{CH}_{4}$ flow rate to $200 \mathrm{sccm}$. The SEM images, as shown in Figure 2b, show that the density of $\mathrm{NbC}$ increases with the flow rate of $\mathrm{CH}_{4}$.
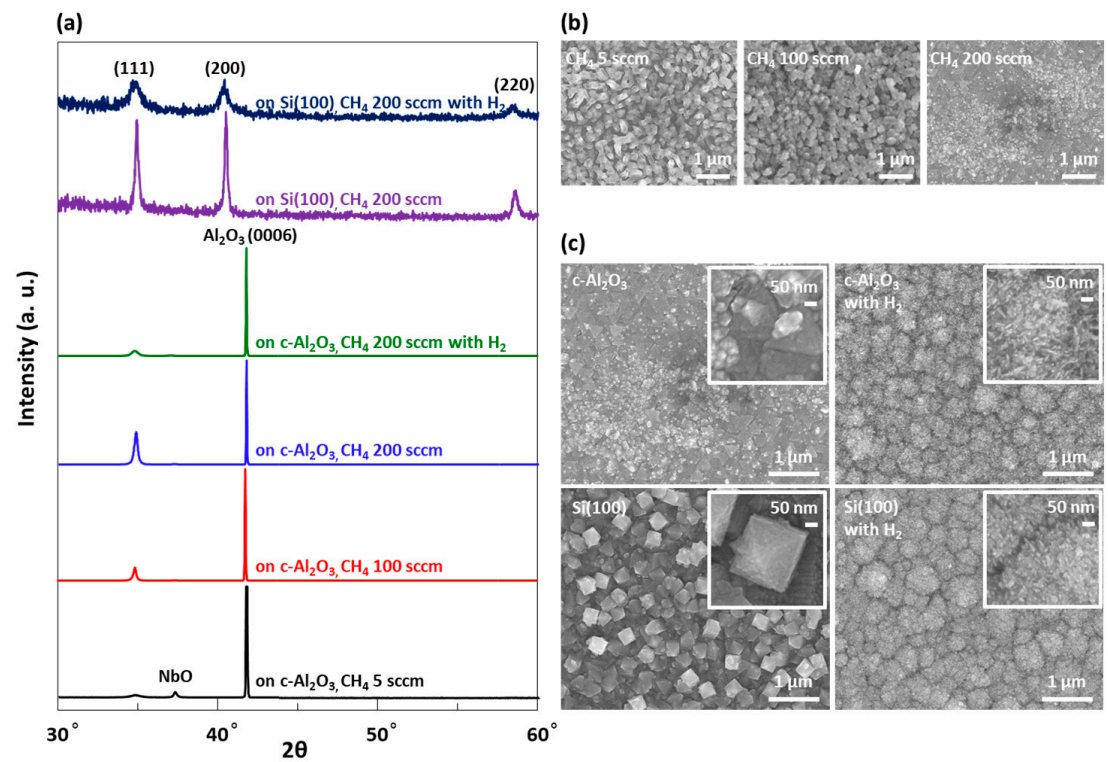

Figure 2. (a) XRD patterns of $\mathrm{NbC}$ films grown using different conditions. The intensities of the XRD patterns (the top two patterns) of $\mathrm{NbC}$ grown on $\mathrm{Si}$ (100) were magnified 350 times compared with those (the bottom four patterns) of $\mathrm{NbC}$ grown on c-plane sapphire; (b) SEM images of NbC films grown at different $\mathrm{CH}_{4}$ gas flow rates; (c) SEM images of $\mathrm{NbC}$ films grown at different conditions. All the four $\mathrm{NbC}$ samples were grown at a $\mathrm{CH}_{4}$ flow rate of $200 \mathrm{sccm}$.

In addition, the $\mathrm{NbC}$ growth varied depending on the type of substrate. A comparison of $\mathrm{NbC}$ samples grown at the $\mathrm{CH}_{4}$ flow rate of $200 \mathrm{sccm}$ on c-plane sapphire and $\mathrm{Si}(100)$ shows that the $\mathrm{NbC}$ 
film deposited on the c-plane sapphire exhibits only the (111) peak, while that on $\mathrm{Si}$ (100) exhibits (200) and (220) peaks in addition to the (111) peak in the XRD pattern. The peak intensity is higher for the $\mathrm{NbC}$ film grown on the $c$-plane sapphire. The $\mathrm{NbC}$ (111) peak intensity of the $\mathrm{NbC}$ film deposited on the c-plane sapphire is approximately 100 times higher than that of the film on $\mathrm{Si}$ (100). This indicates that the $\mathrm{NbC}$ film deposited on the c-plane sapphire has a preferential orientation of the (111) plane, whereas that on the $\mathrm{Si}(100)$ substrate is relatively randomly oriented and has a low crystallinity. The SEM images, see Figure 2c, show dense triangular domains of $\mathrm{NbC}$ on the $c$-plane sapphire and less-dense octahedral-shape $\mathrm{NbC}$ domains on $\mathrm{Si}$ (100).

We also analyzed changes in crystallinity of $\mathrm{NbC}$ in the presence of $\mathrm{H}_{2}$. The XRD patterns show that the addition of $\mathrm{H}_{2}$ flow $\left(200 \mathrm{sccm}\right.$ ) under the same $\mathrm{CH}_{4}$ flow rate weakens the intensity and sharpness of the peaks on both c-plane sapphire and $\mathrm{Si}(100)$ substrates, which suggests that the presence of $\mathrm{H}_{2}$ decreases their crystallinity. This can be also observed in the SEM images, see Figure 2c. In the absence of $\mathrm{H}_{2}, \mathrm{NbC}$ grew in an angular shape, whereas in the presence of $\mathrm{H}_{2}$, the grown $\mathrm{NbC}$ had a rough surface. For quantitative comparison, we used the Scherrer equation on the $\mathrm{NbC}$ (111) peak and the calculated crystallite size of each film was as follows: $37 \mathrm{~nm}$ (on c-plane sapphire, without $\mathrm{H}_{2}$ ), $40 \mathrm{~nm}$ (on $\mathrm{Si}$, without $\mathrm{H}_{2}$ ), $20 \mathrm{~nm}$ (on c-plane sapphire, with $\mathrm{H}_{2}$ ) [28]. The above results may be related to the property of $\mathrm{NbC}$ that enables it to capture hydrogen. For example, $\mathrm{NbC}$ precipitates added to alloys such as steel act as hydrogen traps to interfere with hydrogen diffusion, thereby improving the resistance to hydrogen-induced cracking (HIC) of steel $[29,30]$. The swollen shape of the films grown with $\mathrm{H}_{2}$ shows the possibility for this phenomenon.

Figure 3 shows TEM images (Figure $3 \mathrm{a}, \mathrm{c}$ ) of the $\mathrm{NbC}$ film grown on sapphire without $\mathrm{H}_{2}$ and its corresponding selected-area electron diffraction (SAED) pattern, see Figure $3 b$, obtained from the area in Figure 3a. In the SAED pattern, the distances from the center to each ring are $3.9821 / \mathrm{nm}(0.251 \mathrm{~nm})$, $4.5721 / \mathrm{nm}(0.219 \mathrm{~nm}), 6.4991 / \mathrm{nm}(0.154 \mathrm{~nm})$, and $7.681 / \mathrm{nm}(0.130 \mathrm{~nm})$, and these correspond to the (111), (200), (220), and (311) lattice planes of $\mathrm{NbC}$, respectively. The ring-shaped patterns in the SAED pattern indicate that the sample is polycrystalline and that it has no symmetry. It is considered that this is the result of overlapping $\mathrm{NbC}$ particles during the preparation of the TEM sample because the $\mathrm{NbC}$ grown on c-plane sapphire has a (111) preferred orientation along the out-of-plane direction and has a six-fold symmetry in the in-plane direction (the in-plane analysis of the sample will be discussed in detail in the section below). The high-resolution TEM image, shown in Figure 3c, shows grains with different orientations and grain boundaries.

\subsection{Epitaxial Growth Mechanism}

The correlation between the (0001) plane of sapphire $\left(\mathrm{Al}_{2} \mathrm{O}_{3}\right)$ and (111) plane of $\mathrm{NbC}$ was investigated to explain the observation that $\mathrm{NbC}$ on $c$-plane sapphire grows preferentially with the (111) plane. The coincident site lattice (CSL) [31-34] or domain-matching epitaxy (DME) theory [35-38] shows that the $\mathrm{NbC}$ (111) plane could grow epitaxially on the $\mathrm{Al}_{2} \mathrm{O}_{3}(0001)$ plane. Figure 4a shows schematic diagrams of this epitaxial relationship. The in-plane lattice mismatch between $\mathrm{Al}_{2} \mathrm{O}_{3}(0001)$ and $\mathrm{NbC}(111)$ is: $f=\left(a_{\mathrm{Al}_{2} \mathrm{O}_{3}}-a_{\mathrm{NbC}(111)}\right) / a_{\mathrm{Al}_{2} \mathrm{O}_{3}}=(0.481 \mathrm{~nm}-0.319 \mathrm{~nm}) /(0.481 \mathrm{~nm})=0.34$, which is a very large value; therefore, an epitaxial growth is unlikely. However, the $\mathrm{O}-\mathrm{O}$ interatomic distance along the [1-100] direction, at $30^{\circ}$ from the [2-1-10] direction, is $0.275 \mathrm{~nm}$. When the [1-100] direction on the (0001) plane of $\mathrm{Al}_{2} \mathrm{O}_{3}$ and [10-1] direction on the $\mathrm{NbC}$ (111) plane are arranged to be parallel, as shown in the top-view schematic diagram in Figure 4a, the $f$ value is reduced to 0.16; therefore, an epitaxial growth can be expected. In this direction, as shown in the side-view schematic in Figure 4a, seven times the $\mathrm{O}-\mathrm{O}$ distance of $\mathrm{Al}_{2} \mathrm{O}_{3}(0.275 \mathrm{~nm} \times 7=1.925 \mathrm{~nm})$ is almost equal to six times the $\mathrm{Nb}-\mathrm{Nb}$ distance of $\mathrm{NbC}(0.319 \mathrm{~nm} \times 6=1.914 \mathrm{~nm})$. 

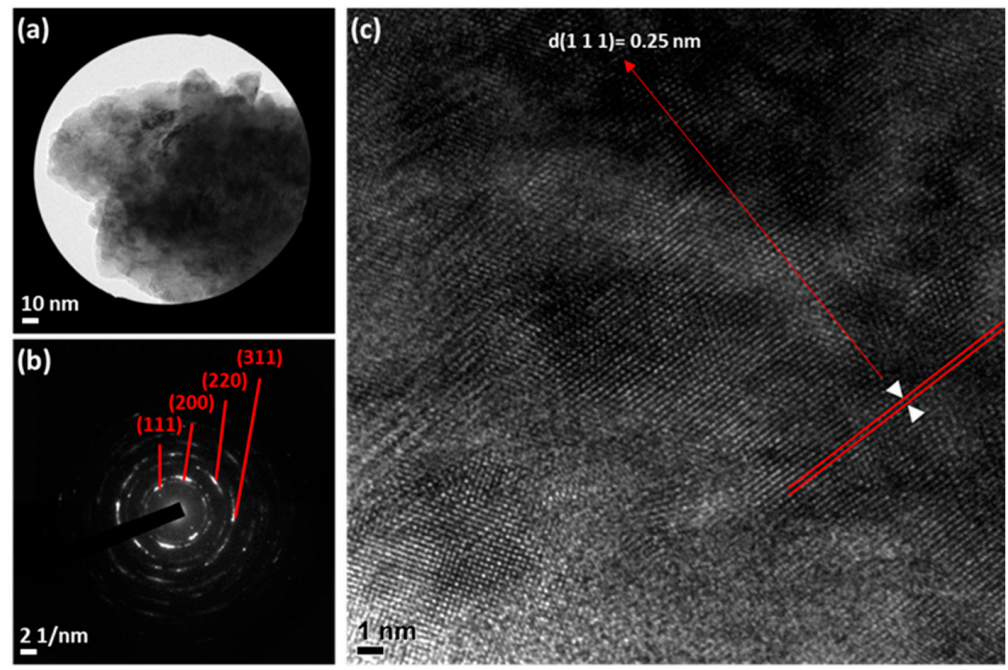

Figure 3. (a) Low-magnification TEM image; (b) corresponding SAED pattern; (c) high-resolution TEM image of the $\mathrm{NbC}$ film grown without $\mathrm{H}_{2}$ on the $c$-plane sapphire.

(a)

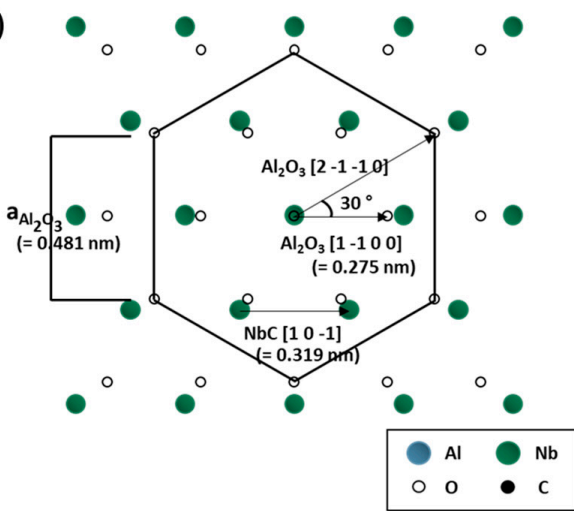

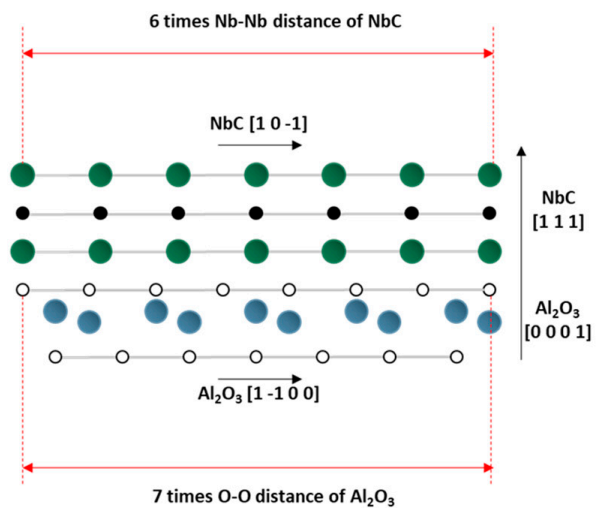

(c) (b)

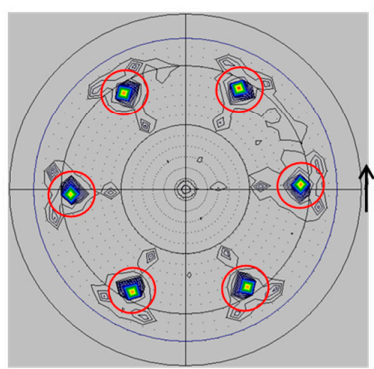

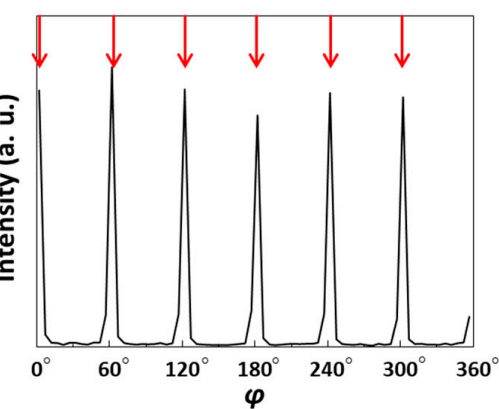

Figure 4. (a) Schematic diagrams showing the epitaxial relationship between the (0001) plane of the c-plane sapphire $\left(\mathrm{Al}_{2} \mathrm{O}_{3}\right)$ substrate and $\mathrm{NbC}(111)$ plane: Top (left) and side views (right); (b) X-ray pole figure of the $\mathrm{NbC} / \mathrm{c}$-sapphire system measured at a $2 \theta$ angle of $40.32^{\circ}$ for the $\mathrm{NbC}(200)$ peak; (c) Azimuthal $(\varphi)$ scan data measured at a $\chi$ angle of $55^{\circ}$.

Through this epitaxial relationship, the $\mathrm{NbC}$ is expected to have a six-fold symmetry on $c$-plane sapphire, and we performed the $\mathrm{X}$-ray pole figure analysis to show this. When the pole figure was measured at a $2 \theta$ angle of $40.32^{\circ}$, the six-fold symmetry of $\mathrm{NbC}$ was confirmed as shown in Figure $4 \mathrm{~b}, \mathrm{c}$. The $2 \theta$ angle of $40.32^{\circ}$ is the angle for the (200) plane of $\mathrm{NbC}$, and we can see that diffraction occurs, having $60^{\circ}$ intervals when the chi $(\chi)$ angle is tilted by about $55^{\circ}$. This is because the (200) plane of $\mathrm{NbC}$ has an interplanar angle of $54.74^{\circ}$ with respect to the (111) plane of $\mathrm{NbC}$. Therefore, it can be seen that the (111) plane of $\mathrm{NbC}$ has a six-fold symmetry in the in-plane direction as the diffraction appears at intervals of $60^{\circ}$. This result can also be derived from analysis of the (220) plane, which has an interplanar angle of $35.26^{\circ}$ with respect to the (111) plane of $\mathrm{NbC}$ see Figure S2. 


\subsection{Mechanical Property Characterization}

A nanoindentation test was performed to study the variations in the mechanical properties of the $\mathrm{NbC}$ films as a function of the crystal orientation and presence of $\mathrm{H}_{2}$ at the growth stage. Figure 5 shows load-displacement responses of the $\mathrm{NbC}$ films grown in the absence or presence of $\mathrm{H}_{2}$ on the c-plane sapphire, and that for the growth in the presence of $\mathrm{H}_{2}$ on $\mathrm{Si}(100)$. A measurement for $\mathrm{NbC}$ deposited without $\mathrm{H}_{2}$ on $\mathrm{Si}(100)$ was not possible owing to the surface morphology of the sample, as shown in Figure 2c. The penetration depth is measured by the difference in height between the indenter and reference tip. However, in the case of this sample, we could hardly adjust the zero point of the indenter with the reference tip. In Figure 5a, the penetration depth was only several tens of nanometers, which reveals that the $\mathrm{NbC}$ film grown in the absence of $\mathrm{H}_{2}$ on the $c$-plane sapphire is a very hard material. The hardness and elastic modulus of the sample were 10.94 GPa and $308.22 \mathrm{GPa}$, respectively. The values were automatically calculated with the Oliver-Pharr method [39,40]. At a penetration depth of approximately $45 \mathrm{~nm}$, the parabolic curve is flattened, which can be regarded as a fracture due to the brittleness of the sample. When elastic modulus and hardness values are calculated with the Oliver-Pharr method in nanoindentation analysis, plastic depth $\left(h_{\mathrm{p}}\right)$ is used [41,42]. Plastic depth is defined as the depth of the indenter in contact with the sample under load, and it can be obtained from the load-penetration depth curve. The $x$-intercept of the tangent line to the unloading curve at maximum load is the plastic depth. However, in our sample's curve, the plastic depth value was obtained was larger than the actual value due to the increase of the penetration depth caused by the fracture as explained above. Therefore, it can be concluded that this affected the calculation of the values of elastic modulus and hardness of our sample. Since it was confirmed that the thickness of the film was about $300 \mathrm{~nm}$ with the cross-sectional SEM image, see Figure S3, the above data can be regarded as a result of the film not affected by the substrate (The thicknesses of the films grown with $\mathrm{H}_{2}$ are more than $1 \mu \mathrm{m}$ ). On the other hand, in the case of the $\mathrm{NbC}$ films grown in the presence of $\mathrm{H}_{2}$, initially, the slope is small, and the penetration depth is large. This is followed by a rapid increase in the slope, as shown in Figure $5 \mathrm{~b}$. The calculated hardness and elastic modulus of the film on $c$-plane sapphire with $\mathrm{H}_{2}$ were 0.75 and $54.52 \mathrm{GPa}$, and those values of the film on $\mathrm{Si}$ (100) with $\mathrm{H}_{2}$ were 0.21 and $50.51 \mathrm{GPa}$. We discussed above that $\mathrm{H}_{2}$ degraded the crystallinity of $\mathrm{NbC}$ and changed the surface morphology to a porous one, see Figure 2a,c and Figure S3. Therefore, it is considered that the surface of the material was softened owing to the degraded crystallinity and the changed surface morphology upon the introduction of $\mathrm{H}_{2}$. In addition, a comparison of the $\mathrm{NbC}$ films grown with $\mathrm{H}_{2}$ on the c-plane sapphire and $\mathrm{Si}(100)$ shows that the $\mathrm{NbC}$ film grown on the c-plane sapphire, which has the preferred orientation of the (111) plane, is stronger than the $\mathrm{NbC}$ film grown on $\mathrm{Si}(100)$, which has a random orientation and low crystallinity.

(a)

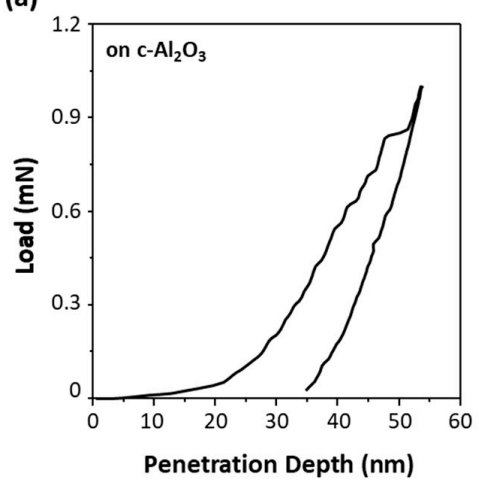

(b)

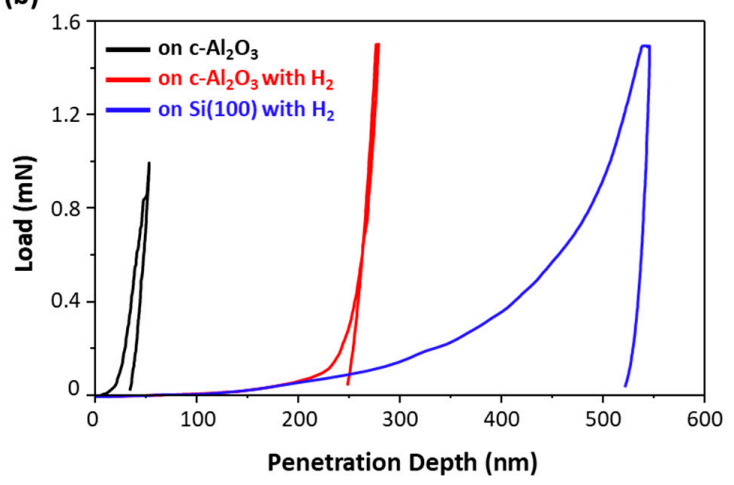

Figure 5. (a) Nanoindentation load-penetration depth curve for the $\mathrm{NbC}$ film grown without $\mathrm{H}_{2}$ on the $c$-plane sapphire; (b) comparison of load-penetration depth curves of the $\mathrm{NbC}$ films grown under different conditions. 


\section{Conclusions}

The $\mathrm{NbC}$ film grown on c-plane sapphire had a preferential orientation of the (111) plane, which could be explained by the CSL and DME theory. We deposited $\mathrm{NbC}$ using $\mathrm{CH}_{4}$ as a carbon source and confirmed that $\mathrm{CH}_{4}$ also acted as a reducing agent to remove the oxide formed by the reaction between oxygen remaining in the furnace and niobium precursor. On the $\mathrm{Si}(100)$ substrate, $\mathrm{NbC}$ grew without any preferential orientation and was softer than the $\mathrm{NbC}$ film grown on the $c$-plane sapphire with the preferential orientation of the (111) plane. Furthermore, we compared the differences in $\mathrm{NbC}$ growth between the samples obtained in the presence and absence of $\mathrm{H}_{2}$. The results showed that $\mathrm{H}_{2}$ at the growth stage lowered the crystallinity of $\mathrm{NbC}$ and led to a rough and soft surface.

Supplementary Materials: The following are available online at http:/ /www.mdpi.com/2079-6412/8/11/379/s1, Figure S1: XRD patterns (logarithmic scale) of NbC films grown at different conditions; Figure S2: (a) X-ray pole figure of the $\mathrm{NbC} / \mathrm{c}$-sapphire system measured at a $2 \theta$ angle of $58.34^{\circ}$ for the $\mathrm{NbC}(220)$ peak; (b) Azimuthal $(\varphi)$ scan data measured at a $\chi$ angle of $35^{\circ}$; Figure S3: Cross-sectional SEM images of $\mathrm{NbC}$ films.

Author Contributions: Conceptualization, K.-W.K., B.J.K., H.K.Y., and J.-Y.C.; Methodology, K.-W.K., B.J.K., H.K.Y., and J.-Y.C.; Validation, K.-W.K., S.H.L., H.K.Y., and J.-Y.C.; Formal Analysis, K.-W.K., S.H.L., J.L., H.K.Y., and J.-Y.C.; Investigation, K.-W.K., S.H.L., H.K.Y., and I.J.C.; Resources, K.-W.K., S.H.L., H.K.L., and T.N.; Data Curation, K.-W.K., S.H.L., H.K.Y., and B.J.K.; Writing-Original Draft Preparation, K.-W.K.; Writing-Review and Editing, K.-W.K., H.K.Y., and J.-Y.C.; Visualization, B.J.K., B.J.J., and T.N.; Supervision, H.K.Y., and J.-Y.C.; Project Administration, B.J.K.; Funding Acquisition, J.-Y.C.

Funding: This research was supported by the Basic Science Research Program through the National Research Foundation of Korea (NRF), funded by the Ministry of Education, Science, and Technology [NRF-2018R1D1A1B07050253].

Acknowledgments: We gratefully thank Tae-Woo Lee of the Research Institute of Advanced Materials (RIAM) for the XRD and Pole figure measurement.

Conflicts of Interest: The authors declare no conflict of interest.

\section{References}

1. Cuppari, M.G.D.V.; Santos, S.F. Physical properties of the NbC carbide. Metals 2016, 6, 250. [CrossRef]

2. Quesne, M.G.; Roldan, A.; de Leeuw, N.H.; Catlow, C.R.A. Bulk and surface properties of metal carbides: Implications for catalysis. Phys. Chem. Chem. Phys. 2018, 20, 6905-6916. [CrossRef] [PubMed]

3. Niu, T. Old materials with new properties II: The metal carbides. Nano Today 2018, 18, 12-14. [CrossRef]

4. Abolaji, R.S.; Bingxue, Z.; Anbalgam, K.; Thomas, T.; Minghui, Y. Synthesis and application of nano-structured metal nitrides and carbides: A review. Prog. Solid State Chem. 2018, 50, 1-15.

5. Amaya, A.; Piamba, O.; Olaya, J. Improvement of corrosion resistance for gray cast iron in palm biodiesel application using thermoreactive diffusion niobium carbide ( $\mathrm{NbC})$ coating. Coatings 2018, 8, 216. [CrossRef]

6. Woydt, M.; Huang, S.; Vleugels, J.; Mohrbacher, H.; Cannizza, E. Potentials of niobium carbide (NbC) as cutting tools and for wear protection. Int. J. Refract. Met. Hard Mater. 2018, 72, 380-387. [CrossRef]

7. Montenegro, P.; Gomes, J.; Rego, R.; Borille, A. Potential of niobium carbide application as the hard phase in cutting tool substrate. Int. J. Refract. Met. Hard Mater. 2018, 70, 116-123. [CrossRef]

8. Woydt, M.; Mohrbacher, H.; Vleugels, J.; Huang, S. Niobium carbide for wear protection-tailoring its properties by processing and stoichiometry. Met. Powder Rep. 2016, 71, 265-272. [CrossRef]

9. Nedfors, N.; Tengstrand, O.; Lewin, E.; Furlan, A.; Eklund, P.; Hultman, L.; Jansson, U. Structural, mechanical and electrical-contact properties of nanocrystalline- $\mathrm{NbC} /$ amorphous-C coatings deposited by magnetron sputtering. Surf. Coat. Technol. 2011, 206, 354-359. [CrossRef]

10. Liu, Y.; Kelly, T.G.; Chen, J.G.; Mustain, W.E. Metal carbides as alternative electrocatalyst supports. ACS Catal. 2013, 3, 1184-1194. [CrossRef] [PubMed]

11. Nabil-Moreau, Y.; Cavaliere, S.; Harkness, I.; Hards, G.; Sharman, J.; Jones, D.J.; Rozière, J. Corrosion resistant electrospun niobium carbide nanotube supports for PEMFC cathodes. ECS Trans. 2015, 69, 1221-1226. [CrossRef]

12. Meyer, S.; Nikiforov, A.V.; Petrushina, I.M.; Köhler, K.; Christensen, E.; Jensen, J.O.; Bjerrum, N.J. Transition metal carbides $\left(\mathrm{WC}, \mathrm{Mo}_{2} \mathrm{C}, \mathrm{TaC}, \mathrm{NbC}\right.$ ) as potential electrocatalysts for the hydrogen evolution reaction (HER) at medium temperatures. Int. J. Hydrogen Energy 2015, 40, 2905-2911. [CrossRef] 
13. Coy, E.; Yate, L.; Valencia, D.P.; Aperador, W.; Siuzdak, K.; Torruella, P.; Azanza, E.; Estrade, S.; Iatsunskyi, I.; Peiro, F.; et al. High electrocatalytic response of a mechanically enhanced $\mathrm{NbC}$ nanocomposite electrode toward hydrogen evolution reaction. ACS Appl. Mater. Interfaces 2017, 9, 30872-30879. [CrossRef] [PubMed]

14. Liu, F.; Liu, P.; Peng, F.; Liu, J.; He, D. Hardness and compression behavior of niobium carbide. High Press. Res. 2017, 37, 244-255. [CrossRef]

15. Kim, B.R.; Woo, K.D.; Yoon, J.K.; Doh, J.M.; Shon, I.J. Mechanical properties and rapid consolidation of binderless niobium carbide. J. Alloys Compd. 2009, 481, 573-576. [CrossRef]

16. Yate, L.; Coy, L.E.; Wang, G.; Beltrán, M.; Díaz-Barriga, E.; Saucedo, E.M.; Ceniceros, M.A.; Załęski, K.; Llarena, I.; Möller, M.; et al. Tailoring mechanical properties and electrical conductivity of flexible niobium carbide nanocomposite thin films. RSC Adv. 2014, 4, 61355-61362. [CrossRef]

17. Li, H.; Song, Q.; Xu, Q.; Chen, Y.; Xu, L.; Man, T. Electrochemical synthesis of core-shell-structured NbC-Fe composite powder for enforcement in low-carbon steel. Materials 2017, 10, 1257. [CrossRef] [PubMed]

18. Klug, J.A.; Proslier, T.; Elam, J.W.; Cook, R.E.; Hiller, J.M.; Claus, H.; Becker, N.G.; Pellin, M.J. Atomic layer deposition of amorphous niobium carbide-based thin film superconductors. J. Phys. Chem. C 2011, 115, 25063-25071. [CrossRef]

19. Woydt, M.; Mohrbacher, H. Friction and wear of binder-less niobium carbide. Wear 2013, 306, $126-130$. [CrossRef]

20. Agte, C.; Moers, K. Methoden zur reindarstellung hochschmelzender carbide, nitride und boride und beschreibung einiger ihrer eigenschaften. Z. Anorg. Allg. Chem. 1931, 198, 233-275. (In German) [CrossRef]

21. Naumenko, V.Y. Poluchenie karbidov perekhodnykh metallov IV-V grupp v oblastyakh ikh gomogennosti [preparation carbides of transition metals of IV-V groups in their areas homogeneity]. Poroshkovaya Metal. Sov. Powder Metall. Met. Ceram. 1970, 10, $20-22$.

22. Powell, R.M.; Skocpol, W.J.; Tinkham, M. Preparation and superconducting properties of ultrafine powders and sintered compacts of $\mathrm{NbC}$ and NbN. J. Appl. Phys. 1977, 48, 788-794. [CrossRef]

23. Crayton, P.H.; Gridly, M.C. Vapour-phase synthesis of submicron tantalum carbide. Powder Metall. 1971, 14, 78-85. [CrossRef]

24. Da Silva, V.T.; Schmal, M.; Oyama, S.T. Niobium carbide synthesis from niobium oxide: Study of the synthesis conditions, kinetics, and solid-state transformation mechanism. J. Solid State Chem. 1996, 123, 168-182. [CrossRef]

25. Xu, G.Y.; Li, J.B.; Huang, Y.; Xie, Z.P. Fabrication and morphology of different color $\mathrm{NbC}_{x}$ whiskers. J. Cryst. Growth 1999, 200, 143-147. [CrossRef]

26. Oyama, S.T.; Schlatter, J.C.; Metcalfe, J.E., III; Lambert, J.M., Jr. Preparation and characterization of early transition metal carbides and nitrides. Ind. Eng. Chem. Res. 1988, 27, 1639-1648. [CrossRef]

27. Xu, Y.X.; Lu, J.T.; Li, W.Y.; Yang, X.W. Oxidation behaviour of Nb-rich Ni-Cr-Fe alloys: Role and effect of carbides precipitates. Corros. Sci. 2018, 140, 252-259. [CrossRef]

28. Scherrer, P. Bestimmung der inneren struktur und der größe von kolloidteilchen mittels röntgenstrahlen. In Kolloidchemie ein Lehrbuch; Springer: Berlin, Germany, 1912; pp. 387-409. (In German)

29. Cui, Q.; Wu, J.; Xie, D.; Wu, X.; Huang, Y.; Li, X. Effect of nanosized NbC precipitates on hydrogen diffusion in $\times 80$ pipeline steel. Materials 2017, 10, 721. [CrossRef] [PubMed]

30. Silverstein, R.; Eliezer, D.; Boellinghaus, T. Hydrogen-trapping mechanisms of TIG-welded 316L austenitic stainless steels. J. Mater. Sci. 2018, 53, 10457-10468. [CrossRef]

31. Saitoh, K.I.; Kuramitsu, K.; Sato, T.; Takuma, M.; Takahashi, Y. Molecular dynamics study on deformation mechanism of grain boundaries in magnesium crystal: Based on coincidence site lattice theory. J. Mater. Sci. 2018, 2018, 4153464. [CrossRef]

32. Trampert, A.; Brandt, O.; Ploog, K.H. Crystal structure of group iii nitrides. In Semiconductors and Semimetals; Elsevier: Amsterdam, The Netherlands, 1997; Volume 50, pp. 167-192.

33. Sun, C.J.; Kung, P.; Saxler, A.; Ohsato, H.; Haritos, K.; Razeghi, M. A crystallographic model of (00·1) aluminum nitride epitaxial thin film growth on (00-1) sapphire substrate. J. Appl. Phys. 1994, 75, 3964-3967. [CrossRef]

34. Mykura, H.; Bansal, P.S.; Lewis, M.H. Coincidence-site-lattice relations for MgO-CdO interfaces. Philos. Mag. A 1980, 42, 225-233. [CrossRef] 
35. Sánchez, F.; Bachelet, R.; de Coux, P.; Warot-Fonrose, B.; Skumryev, V.; Tarnawska, L.; Zaumseil, P.; Schroeder, T.; Fontcuberta, J. Domain matching epitaxy of ferrimagnetic $\mathrm{CoFe}_{2} \mathrm{O}_{4}$ thin films on $\mathrm{Sc}_{2} \mathrm{O}_{3} / \mathrm{Si}$ (111). Appl. Phys. Lett. 2011, 99, 211910. [CrossRef]

36. Liu, W.R.; Li, Y.H.; Hsieh, W.F.; Hsu, C.H.; Lee, W.; Lee, Y.J.; Hong, M.; Kwo, J. Domain matching epitaxial growth of high-quality $\mathrm{ZnO}$ film using a $\mathrm{Y}_{2} \mathrm{O}_{3}$ buffer layer on $\mathrm{Si}$ (111). Cryst. Growth Des. 2008, 9, $239-242$. [CrossRef]

37. Narayan, J.; Larson, B.C. Domain epitaxy: A unified paradigm for thin film growth. J. Appl. Phys. 2003, 93, 278-285. [CrossRef]

38. Yu, H.K.; Lee, J.L. Growth mechanism of MgO film on Si (100): Domain matching epitaxy, strain relaxation, preferred orientation formation. Cryst. Growth Des. 2010, 10, 5200-5204. [CrossRef]

39. Oliver, W.C.; Pharr, G.M. An improved technique for determining hardness and elastic modulus using load and displacement sensing indentation experiments. J. Mater. Res. 1992, 7, 1564-1583. [CrossRef]

40. Oliver, W.C.; Pharr, G.M. Measurement of hardness and elastic modulus by instrumented indentation: Advances in understanding and refinements to methodology. J. Mater. Res. 2004, 19, 3-20. [CrossRef]

41. Doerner, M.F.; Nix, W.D. A method for interpreting the data from depth-sensing indentation instruments. J. Mater. Res. 1986, 1, 601-609. [CrossRef]

42. Li, X.; Gao, H.; Murphy, C.J.; Caswell, K.K. Nanoindentation of silver nanowires. Nano Lett. 2003, 3, 1495-1498. [CrossRef]

(C) 2018 by the authors. Licensee MDPI, Basel, Switzerland. This article is an open access article distributed under the terms and conditions of the Creative Commons Attribution (CC BY) license (http:/ / creativecommons.org/licenses/by/4.0/). 